\title{
Retraction Note to: Overexpression of interleukins IL-17 and IL-8 with poor prognosis in colorectal cancer induces metastasis
}

\author{
Mohsen Mohammadi ${ }^{1}$ - Maria Kaghazian ${ }^{2}$ - Omid Rahmani ${ }^{3}$ - Koorosh Ahmadi ${ }^{4}$ \\ Elham Hatami ${ }^{5}$ - Katayoun Ziari $^{3}$ - Amir Talebreza ${ }^{6}$
}

Published online: 9 November 2016

(C) International Society of Oncology and BioMarkers (ISOBM) 2016

Retraction Note to: Tumor Biol (2016) 37:7501-7505

DOI 10.1007/s13277-015-4628-z

This article has been retracted at the request of the Editorin-Chief, the International Society of Oncology and BioMarkers (ISOBM) and the Publisher per the Committee on Publication Ethics guidelines. The article shows evidence of irregularities in authorship during the submission process, and there is strong reason to believe that the peer review process was compromised.

As such the validity of the content of this article cannot be verified.

The online version of the original article can be found at http://dx.doi. org/10.1007/s13277-015-4628-z.

Amir Talebreza

dr.amirtalebreza@gmail.com

1 Department of Pharmaceutical Biotechnology, Faculty of Pharmacy, Lorestan University of Medical Sciences, Khorramabad, Iran

2 Department of Biology, Jundishapur University of Medical Sciences, Ahvaz, Iran

3 Department of Pathology, Be'sat Hospital, AJA University of Medical Sciences, Tehran, Iran

4 Department of Emergency Medicine, Alborz University of Medical Sciences, Karaj, Iran

5 Department of Pathology, Loghman Hakim Hospital, Sarakhs, Iran

6 Department of Surgery, AJA University of Medical Sciences, Tehran, Iran 